\title{
Fabrication technique for bio-composite patch repair on laminated structures of CFRP plate
}

\begin{abstract}
Laminated structures are assembled so that the fibre orientation provides most of desired mechanical properties and the matrix largely determines the environmental performance. Composites laminate structures are used in a wide range of applications in aerospace, marine, automotive, surface transport and sports equipment markets. Damage to composite components is not always visible to the naked eye and the extent of damage is best determined for structural components by suitable Non Destructive Test (NDT) methods. Alternatively the damaged areas can be located by simply tapping the composite surface and listening to the sound. The damaged areas give a dull response to the tapping, and the boundary between the good and damaged composite can easily be mapped to identify the area for repair. Awareness of and inspection for composite damage should be included in the regular maintenance schedules for composite structures. Particular attention would be made to areas which are more prone to damage. The repair can be done by using composite itself or bio-composite. Bio-composite is a reinforcement of natural fibre such as plant and a material that formed by matrix or resin. Then repairs to aircraft structures are controlled and should be carried out according to the Aircraft Structural Repair Manual (SRM). For other applications the repaired components would normally be expected to meet the original specifications and mechanical performance requirements. This paper presents the fabrication technique including patch repair by using bio-composite which is kenaf and its aim to give a general approach to composite fabrication on patch repair in all applications. Through the described approach, the life of the structure is expanded and met the properties requirements such as low cost, fairly good mechanical properties, high specific strength, non-abrasive, eco-friendly and bio-degradability characteristics.
\end{abstract}

Keyword: CFRP; Fabrication; Kenaf; Patch repair; Vacuum bagging 